\title{
REVIEW
}

\section{The Key Technologies and Influence Factors of the Information Plat- form Construction for Material Quality Management in Urban Sub- way Project}

\section{Hongning $\mathrm{He}^{1}$, Yufeng $\mathrm{Wu}^{2} *$}

1. Nanjing Institute of Product Quality Inspection, Nanjing, Jiangsu, 210019, China

2. NARI Group Company Co., Ltd (State Grid Electronic Power Research Institute Co., Ltd), Nanjing, Jiangsu, 210003, China

\begin{tabular}{l}
\hline ARTICLE INFO \\
\hline Article history \\
Received: 9 May 2019 \\
Revised: 10 June 2019 \\
Accepted: 10 October 2019 \\
Published Online: 16 October 2019 \\
\hline Keywords: \\
Subway project \\
Information platform for material quality \\
management \\
Key technologies \\
Influence factors
\end{tabular}

\begin{abstract}
A number of factors may affect the quality of subway project during construction such as construction material and construction personnel. Therefore, it is necessary to study about the influence factors of subway project quality. A variety of influence factors can be analyzed and studied through the information platform for material quality management in urban subway project to further ensure the quality of subway project. This paper mainly summarized the significance of the information platform for material quality management in urban subway project, investigated the construction scheme of the information platform for material quality management in urban subway project and analyzed the key technologies and influence factors for information platform construction.
\end{abstract}

\section{The Significance of the Information Plat- form Construction for Material Quality Man- agement in Urban Subway Project}

$\mathrm{A}$ s urbanization continuously accelerates, the subway project has developed rapidly. In subway construction, material is an indispensible and crucial element, whose quality will directly affect the overall quality of subway project. Therefore, to effectively manage material quality is of great importance. With the development of information technology and network technology, every industry is undertaking information reform and development. The information construction for material quality management in urban subway project has

*Corresponding Author:

Yufeng Wu (1986-),

Male, a native of Linyi in Shandong Province, China, Graduated master degree, senior engineer;

Research direction: power grid informationization and visualization technology of power grid system;

Correspondence address: NARI Group Company Co., Ltd (State Grid Electronic Power Research Institute Co., Ltd), No.19 Chengxin Avenue, Jiangning District, Nanjing, Jiangsu, 210003, China;

E-mail:wuyufeng@sgepri.sgcc.com.cn.

Fund Project:

The paper is sponsored by the Science and Technology Plan Center of National Market Regulatory Administration Bureau (Project No.: 2017QK192). 
become an important way to promote project construction and stimulate the development of construction industry. Subway project is one of the above projects. The information platform construction of material quality management in urban subway project to manage the quality of a variety of materials is of great significance in accelerating subway construction, reducing construction costs and ensuring project quality.

\section{The Construction Scheme of the Informa- tion Platform for Material Quality Manage- ment in Urban Subway Project}

\subsection{The Integration of "Standardization, System- atization and Intelligence" for the Information Platform of Material Quality Management in Ur- ban Subway Project}

The standardized, systematic and intelligent construction should be actively implemented in the information platform of material quality management in urban subway project. Standardization, Systematization and Intelligence should be effectively integrated to give full play to the underlying efficiency of the information platform.

\subsubsection{Standardization}

To ensure effective information platform for quality management and reliable information sharing, this platform should be standardized. The standardization can mainly be demonstrated in the following aspects: Firstly, unified element codes and standardized management; secondly, core elements for subway project including construction personnel, material and equipment should be archived to further ensure standardized management for archival data; thirdly, the standardization inspection should be conducted for each item in subway project and standardized inspection frequency should be guaranteed to give full play to the role of inspection; fourthly, onsite sampling and evidence acquisition should be implemented in subway project to ensure the quality of subway project, therefore, sampling and evidence acquisition should be standardized to provide effective evidences for subway project quality; lastly, inspection procedure should be standardized. The standardized inspection procedure can ensure effective inspection results to some extent to further promote the progress of subway construction ${ }^{[1]}$.

\subsubsection{Systemization}

Normally, construction project is featured in long cycle, large investment and massive contents. The construction should be systemized and methodized during the entire process. Therefore, the information platform for material quality management in subway project should also be systemized during construction. The systemization can mainly be illustrated in the following aspects: The first is systematic and automatically closed-loop management for the entire quality inspection process, which starts from the registration of personnel, materials and equipment. The basic materials and daily quality inspection records should be archived. The defective products should be effectively controlled and summarized. The systematic management is a way to sort and summarize information and data about subway project for future query and use. The second is to traceable management for personnel, materials and equipment. Take equipment for example, equipment management includes real-time tracking and records-making about procurement, transport, construction and utilization to further understand the status of the equipment ${ }^{[2]}$.

\subsubsection{Intelligence}

Intelligence is what modern construction project pursues, and it is the same case with subway project. Therefore, this information platform should also be intelligent to further ensure the quality and safety of subway construction. The intelligence can mainly be interpreted in the following aspects: The first is dynamic analysis on quality issues to timely detect and analyze issues. The second is to intelligent alarms on quality risks, which is to predict potential quality risks and establish alarm mechanism to automatically provide alarms for risky areas, thus to reduce quality risk factors and the impact caused by risks to some extent. The third is intelligent decision-making by pilot, which is to effectively monitor each item of subway project and make intelligent decisions, thus to ensure the accuracy of decisions ${ }^{[3]}$.

\subsection{Four Core Elements in Platform Management}

The quality supervision platform for subway project is an important part of the information platform for material quality management in subway project, which mainly includes four core elements: construction personnel, construction material and construction equipment as well as construction scheme. Specifically, Construction Personnel, personnel's basic information, qualifications, certificates, appraisal and credits are mainly recorded in the quality supervision platform for future query and use. Construction Material, it is well known that construction material costs account for more than half of the total construction cost. So it is quite necessary to effectively supervise and monitor construction materials. The quality inspections on raw materials and components, semi-finished and finished products as well as concrete are mainly included in this platform. Construction Equipment, it is an important physical foundation of subway project. The equipment 
quality directly affects the progress and quality of subway construction. Therefore, equipment files, acceptance, inspection and maintenance, hazard rectification and abnormal warnings should be included in this platform to ensure the normal working conditions of the equipment. Construction Scheme; it is a guideline for subway construction, which determines the construction procedure and technology during the project. The review and approval for inspection reports and instructions as well as the supervisions for project review records and construction process should be included in this platform to further ensure the overall quality of subway project ${ }^{[4]}$.

\subsection{The Objectives of Information Platform Con- struction}

The information platform construction mainly includes four objectives, which are code unification, process supervision, and abnormal warnings as well as data analysis. Specifically, Code Unification refers to the unified codes for personnel, materials, equipment and documents in accordance with agreed norms on the information platform to lay a solid foundation for standardized business operation and management. Process Supervision refers to specific process supervision and management for personnel, materials, equipment and construction scheme on this information platform, which includes qualification review, trainings and appraisals as well as audit management for personnel, onsite inspection management for materials, archival, daily inspection, repair and maintenance for equipment and archival, scheme assessment and process supervision management for construction, to finally realize the closed-loop management for the overall construction process. Abnormal warnings refer to the management for specific assessment indexes and business processes to actively provide warnings about abnormal business (overdue or defective) on this information platform to further timely remind users and effectively avoid risks. Data Analysis refers to data statistics about personnel, materials, equipment, agencies, time and schemes on this information platform to provide data support for leaders' business decision-making ${ }^{[5]}$.

\section{The Construction Process and Key Tech- nologies of the Information Platform for Ma- terial Quality Management in Urban Subway Project}

\subsection{Platform Construction}

Four aspects should be taken into account in the initial periods during platform construction, which are talents management, hardware facility procurement, system development and maintenance as well as information collection and processing. The specific details are as follows:

\subsubsection{Talents Construction}

Talents play a crucial role in the information platform construction including platform development, operation and maintenance. Specifically, government affairs application departments should be responsible for developing the platform, mainly including planning and designing the information platform for subway materials as well as application technology and services. The technical department should be responsible for platform operation, mainly updating materials and prices in the information platform for subway materials. The system operation department should be responsible for platform maintenance, which mainly includes the planning, construction, operation, maintenance of network platform as well as the operation and maintenance of portal websites and system platform. These jobs require talents with excellent professional competence and strong comprehensive quality as well as cooperation among different departments to lay a solid foundation for the information platform construction for subway materials.

\subsubsection{Hardware Facility}

The hardware facility construction is an important content for the information platform construction. We should follow the principles of high technology, high standard and high starting-point during actual construction. Hardware facility mainly refers to network hardware, mainly including network server, work station, router, repeater and interchanger as well as office desktop for each individual.

\subsubsection{Application System Construction}

The application system construction mainly consists of two parts: database selection and workbench. Database mainly includes storage database and analysis database, whose functions are data storage and online data statistics and analysis, query and mining respectively. The workbench mainly consists of business to be supported by the platform, which is the business scope of materials to be provided by the information platform of subway materials to further provide evidence for subway construction.

\subsubsection{Data Collection and Processing}

Data collection and processing mainly includes information collection, analytical statistics and professional service. Specifically, information collection is to collect, analyze and sort out the information about subway materials. Analytical statistics is to the function of providing information statistics, query and analysis. Professional service mainly refers to the basic service associated with 
material information like function-based access, mails and messages.

\subsection{The Key Technologies $s$ of the Information Platform Construction for Subway Materials}

\subsubsection{Digital Technology}

With the continuous progress of science and technology, digital technology develops rapidly, which has been widely used in a variety of fields. Digital technology is a basic technology for the information platform construction of material management in subway project. This technology is the driving force of today's computer technology. Digital technology is to translate a variety of information with the help of equipment into the digits that can be identified by computer for further digital processing, transport and storage. As information processing includes encoding, compression and decoding by computer during calculation and storage, so it is also called as computer digital technology. The digital technology has been applied in the information platform construction of material management in subway project for digital processing against material information and translating the real information like model, material and price into a variety of information on the information platform for future query. Meanwhile, this technology also plays an important role in information input and exchange ${ }^{[6]}$.

\subsubsection{Cloud Computing Technology}

Currently, cloud computing technology is a hot information technology, which has the advantages of strong reliability, high security and excellent flexibility. Therefore, it has a broad prospect for development. Cloud storage technology and cloud computing technology have been widely used in information resource sharing. It is the same case in the information platform construction of subway material management. The application of the technology has tremendously reduced the hardware demands for computer equipment based on virtual cloud while improving the utilization efficiency of existing computer. Besides, efficient cloud computing and accurate calculation will enhance the operation efficiency of the information platform and reduce construction costs.

\subsubsection{Internet of Things Technology}

The Internet of Things Technology is a derivative of the Internet growing from the Internet, which is characterized by widespread contents and massive functions. The key technologies for the Internet of Things Technology include sensor technology, RFID technology and embedded system technology. Specifically, sensor technology is to translate simulated signals and digital signals through computer for effective information storage. RFID tech- nology refers to automatic identification and management for data and information, through which material data can be effectively identified and managed automatically. Embedded system technology refers to the rapid processing of the information after it is received ${ }^{[7]}$. The application of the Internet of Things Technology has made the information platform for material management in subway project more delicate and intelligent, thus giving full play to the real functions and improving the service capacity of the platform.

\section{How to Improve the Management of the Information Platform for Material Quality Management in Urban Subway Project}

\subsection{Technical Equipment}

Technical equipment is a basis for the information platform construction. In the era of the continuous social and technological development, an increasing number of new materials, new technology and new equipment are making their presence. Therefore, it is quite important to focus on the update and upgrade about technical equipment during the information platform construction. Computer is one of the important equipment for the information platform construction, so it is really important to timely update the hardware and software system of computer so that its functions and performances can be enhanced to constantly promote the modern and intelligent construction of the platform and provide better support for supervision and management ${ }^{[8]}$. Meanwhile, it is necessary to introduce advanced technologies like big data to further improve the management efficiency for material quality information and provide specific information for users.

\subsection{Personnel}

In addition to technical equipment, it is also important to constantly improve personnel's comprehensive quality so as to give full play to the real role of information platform. As main body for the information platform for material management in subway project, personnel's professional competence and business quality directly affects the construction of the information platform. With the development of information and technology, it is necessary for personnel to master certain techniques and skills to so as to make full use of the information platform, give full play to the real function of the information platform, ensure the quality of subway project materials and promote the progress of urban subway project. Besides, it is also important for platform maintenance personnel to have certain techniques and professional quality. When some is- 
sues or loopholes occur on the platform, they must be able to effectively settle issues and fix up loopholes to further ensure the normal operation of the information platform for material management in subway project.

\section{Conclusion}

In summary, targeted at code unification, process supervision, abnormal warnings and data analysis, the information platform for material management in urban subway project is a platform based on digital technology, cloud computing technology and database technology. It is necessary to focus on improving personnel's skills and abilities, updating technique and equipment as well as data compatibility and sharing so that the platform can run more efficiently.

\section{Reference}

[1] Mei Rongjuan. The Research about the Construction Quality Management of Urban Rail Transit Projects in Our Country[J]. Construction \& Design for Project: 2018(4).

[2] Chen Jian. The Discussion about the Demand Analysis and Design of the Information Management for Engineering Materials[J]. Urban Lighting,
2015(4):29-32.

[3] Wang Zhongren. The Discussion about the Material Quality Management for Subway Projects[J]. China Building Materials, 2018, No. 425(5):130-132.

[4] The Realization of Data Management System for Rail Transit Projects and the Data Mining of Their Text Messages[D]. Beijing Jiaotong University, 2009.Wu Fan.

[5] Luo Hanbin, Zhou Ying. The Research about the Information Planning of Subway Project in Wuhan[J]. Journal of Information Technology in Civil Engineering and Architecture, 2010, 2(1):59-63.

[6] Chen Jian. The Discussion about the Demand Analysis and Design of the Information Management for Engineering Materials[J]. Urban Lighting, 2015(4):29-32.

[7] Wang Jing, Zhai Quanli, Zhong Jingbing. The Research about Material Management Information for Subway Construction[J]. Journal of Civil Engineering and Management, 2009, 26(2):80-83.

[8] Zhang Jun. The Reform and Innovation for Subway Project Management through Information[C]. The Dissertation Collections for Urban Rail Transit Management and Technical Innovation Seminars in Qingdao, China in 2014. 